\title{
Current and emerging pharmacological treatments for sarcoidosis: a review
}

This article was published in the following Dove Press journal:

Drug Design, Development and Therapy

II April 2013

Number of times this article has been viewed

\author{
Scott H Beegle' \\ Kerry Barba ${ }^{2}$ \\ Romel Gobunsuy' \\ Marc A Judson' \\ 'Division of Pulmonary and Critical \\ Care Medicine, ${ }^{2}$ Department \\ of Medicine, Albany Medical \\ College, Albany, NY, USA
}

\begin{abstract}
The treatment of sarcoidosis is not standardized. Because sarcoidosis may never cause significant symptoms or organ dysfunction, treatment is not mandatory. When treatment is indicated, oral corticosteroids are usually recommended because they are highly likely to be effective in a relative short period of time. However, because sarcoidosis is often a chronic condition, longterm treatment with corticosteroids may cause significant toxicity. Therefore, corticosteroid sparing agents are often indicated in patients requiring chronic therapy. This review outlines the indications for treatment, corticosteroid treatment, and corticosteroid sparing treatments for sarcoidosis.

Keywords: pulmonary sarcoidosis, extrapulmonary sarcoidosis, treatment, drugs, corticosteroids
\end{abstract}

\section{Introduction}

Sarcoidosis is a multisystem granulomatous disease of unknown cause. The disease most commonly affects the lung, but any organ can be involved. ${ }^{1}$ Sarcoidosis has a variable natural course from an asymptomatic state to a progressive disease, that, on occasion, may be life threatening. Treatment decisions concerning sarcoidosis are problematic for many reasons. First, treatment is often associated with significant side effects. Therefore, treatment may cause more harm than the disease, especially since sarcoidosis may never cause significant symptoms. Second, although sarcoidosis is often well controlled with corticosteroids, many corticosteroid side effects result from chronic use. Therefore, even when sarcoidosis is well controlled with corticosteroids, corticosteroid-sparing medications may be required over time. Third, the treatment of sarcoidosis varies, to some degree, depending on the organ or organs that may be involved. Fourth, because sarcoidosis is not a common disease, minimal evidencebased data exist on which to support treatment decisions. This paper will discuss the decision to treat, drug therapies, and drug toxicities for sarcoidosis. Emphasis will be placed on emerging potential therapies for this disease.

\section{The decision to treat sarcoidosis}

The decision to treat sarcoidosis is a complex one. As mentioned, the disease is often self-limiting and sarcoidosis pharmacotherapy is associated with significant side effects. In this section, some general points concerning the decision to treat sarcoidosis will be addressed.

\section{The treatment of asymptomatic sarcoidosis}

In general, asymptomatic sarcoidosis should not be treated. ${ }^{2,3}$ Many of these patients have minimal physiologic impairment from sarcoidosis; that is the explanation for the 
disease causing no symptoms. These patients often have an excellent prognosis and never develop symptomatic disease or significant organ dysfunction. The risks of subjecting such patients to anti-sarcoidosis therapy, particularly, corticosteroid therapy, usually outweigh the benefits of treatment. It is important to carefully monitor untreated patients for the development of significant symptoms or organ dysfunction that would necessitate therapy. In general, preemptive therapy is not indicated because the granulomatous inflammation from sarcoidosis is often completely reversible, with or without therapy. A potential criticism of this approach is that unchecked granulomatous inflammation can lead to fibrosis and scar formation that is usually irreversible. Although, theoretically, preemptive therapy could avoid such fibrosis, practically speaking, such fibrosis usually requires some months of active disease that usually causes significant symptoms. Specifically, asymptomatic lung, liver, splenic, bone, intrathoracic, and intraabdominal lymph node sarcoidosis involvement very rarely requires treatment.

There are some exceptions to the premise of avoiding treatment of asymptomatic sarcoidosis. Asymptomatic ocular sarcoidosis, especially in the form of sarcoid uveiits, should be treated because it may lead to permanent vision impairment. ${ }^{4}$ For this reason, all patients diagnosed with sarcoidosis should undergo an ophthalmologic evaluation, even if they have no eye symptoms. ${ }^{1}$ Asymptomatic disorders of calcium dysregulation from sarcoidosis could also be considered for treatment. The pathological lesion of sarcoidosis is the granuloma that contains antigen-presenting cells (APCs) such as macrophages. ${ }^{5}$ These APCs contain the enzyme, 1-alpha hydroxylase, which hydroxylates 25-hydroxy vitamin D to 1,25-dihydroxy vitamin D, the active form of the vitamin that can lead to hypercalciuria, hypercalcemia, nephrolithiasis, and renal insufficiency. ${ }^{6,7}$ Asymptomatic nephrolithiasis and renal insufficiency from sarcoidosis should be treated. Mild hypercalcemia that causes no symptoms should probably also be treated, although, often, the serum calcium will return to the normal range with adequate hydration and avoidance of a high-calcium diet. ${ }^{8}$ Asymptomatic hypercalciuria from sarcoidosis does not necessarily require treatment if there is no evidence of hypercalcemia, nephrolithiasis, or renal insufficiency. Certainly, such patients are at increased risk of developing renal problems, and they should be adequately hydrated, avoid excessive calcium intake, and have their renal function carefully monitored. The treatment of asymptomatic cardiac sarcoidosis and neurosarcoidosis is very controversial, as these two forms of sarcoidosis are potentially life-threatening. One study of cardiac sarcoidosis patients found that those without symptoms had an excellent prognosis. However, very few such patients were identified. ${ }^{9}$ Although there is inadequate medical evidence to support a specific approach, we believe that it is not a mandatory requirement to treat asymptomatic cardiac or neurosarcoidosis. We believe that each patient should be evaluated individually, with the decision to treat based on the specific clinical findings (eg, cardiac: presence/absence of sustained ventricular tachycardia/malignant arrhythmias, myocardial performance; neurologic: change in the size of the lesion[s]).

\section{The treatment of multiple organs}

Sarcoidosis often involves multiple organs that may cause treatment decisions to appear complex. We believe that it is essential that treatment decisions concerning sarcoidosis should focus on the treatment indications for each organ in isolation. It is our experience that clinicians may be "overwhelmed" by the number of organs involved, and, in this situation, administer treatment for "systemic sarcoidosis" when a careful analytic approach would suggest there is no specific indication for treatment. When a decision is made to treat sarcoidosis based on specific criteria for specific organ involvement, endpoints for each of these organs should be determined so that therapy can be adjusted in a rational way.

\section{The relationship of disease activity to treatment}

The presence of granulomas from sarcoidosis defines the disease as active. These granulomas deposit in various organs and have the potential to cause organ dysfunction. However, these granulomas may spontaneously remit or cause minimal organ damage, leaving the patient's quality of life unaffected. Figure 1 outlines the general schema of how the granulomatous inflammation of sarcoidosis may affect patients. Many laboratory tests are available to assess disease activity in sarcoidosis, including serum angiotensin-converting enzyme levels and various body scanning techniques. However, in general, the presence of disease activity is a necessary but insufficient criterion on which to base therapy of sarcoidosis. ${ }^{3}$ Rather, the treatment of sarcoidosis should be focused on improving the patient's quality of life. ${ }^{3}$ Therefore, the results of these aforementioned tests of disease activity should not be used to guide therapy. Despite the insufficiency of these tests to determine the need for therapy, evidence of granulomatous inflammation is a necessary requirement for therapy. This is because some sarcoidosis patients have an impaired 


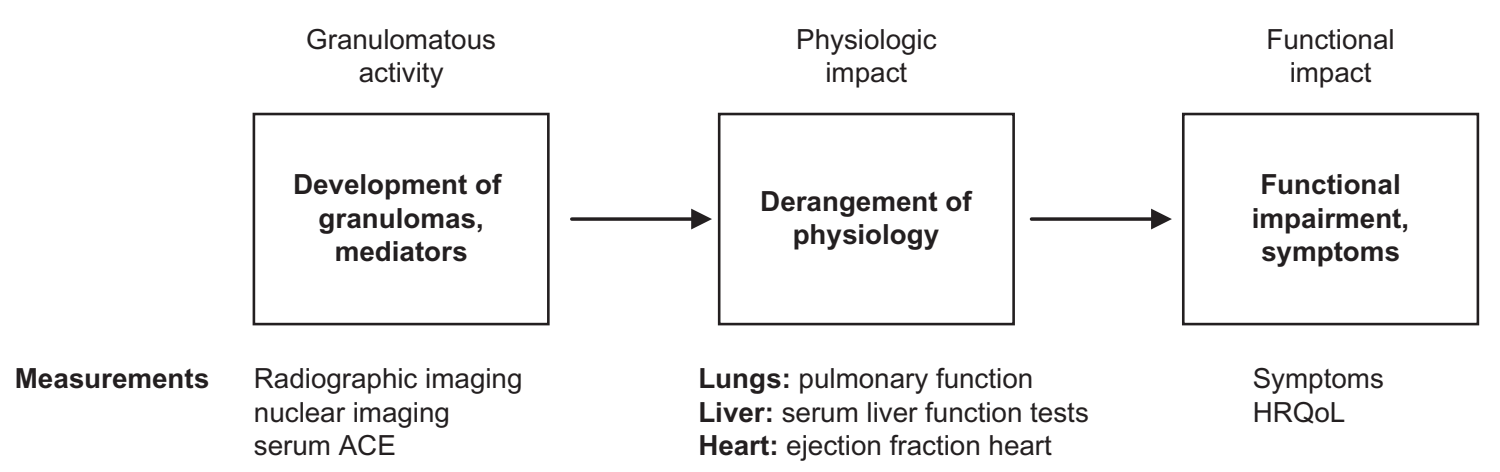

Figure I The pathway from granulomatous inflammation to symptoms in sarcoidosis.

Notes: The figure depicts how the granulomatous inflammation of sarcoidosis leads to patient symptoms. Granulomatous inflammation may not cause a physiologic derangement. Since corticosteroid therapy is associated with many side effects, such patients are usually best served by withholding therapy. Similarly, even if the granulomatous inflammation causes minor physiologic impairment that does not cause symptoms, usually, the patient should not be treated. There are exceptions (see text entitled the treatment of asymptomatic sarcoidosis). Patients should be treated when the physiological impairment attributed to the granulomatous inflammation results in significant symptoms and/or impact upon the patient's quality of life.

Adapted with permission from Judson MA. The treatment of pulmonary sarcoidosis. Respir Med. 20I2;106(I0):135I-136I. ${ }^{3}$

Abbreviations: ACE, angiotensin-converting enzyme; HRQoL, health-related quality of life.

quality of life from previously active sarcoidosis, which has resulted in permanent fibrosis but without evidence of active granulomatous inflammation. Such patients do not require therapy as there is no remaining active disease to treat.

\section{The decision to treat pulmonary sarcoidosis}

Because the lung is the most common organ involved with sarcoidosis and is the most common reason to treat sarcoidosis, the decision to treat pulmonary sarcoidosis in relation to Figure 1 will be discussed. Pulmonary sarcoidosis is problematic to assess, because the appropriate endpoints on which to initiate and adjust therapy are unclear. As mentioned previously, pulmonary symptoms may be discordant with tests reflective of granulomatous inflammation (eg, lung imaging studies) and physiologic impairment (eg, pulmonary function testing) (Figure 1). It is our opinion that treatment should be based primarily on pulmonary symptoms that are thought to be reflective of pulmonary sarcoidosis. ${ }^{3}$ Measurement of pulmonary function tests may be important to support that pulmonary symptoms are caused by pulmonary sarcoidosis. Since chest imaging reflects the granuloma burden, which usually correlates poorly with physiologic change and symptoms related to pulmonary sarcoidosis, ${ }^{10}$ it is not routinely used to determine when to initiate therapy. However, chest imaging should be performed to assess the need for therapy of pulmonary sarcoidosis mainly to exclude alternative cardiopulmonary conditions that could be causing the pulmonary symptoms. ${ }^{3}$ Our general approach to the decision to treat pulmonary sarcoidosis is outlined in Figure 2.

\section{Corticosteroid therapy}

Corticosteroid therapy is considered first line therapy for acute and chronic sarcoidosis in which a decision is made to treat. ${ }^{1-3}$ Despite the nearly universal opinion that corticosteroids are the drug of choice for almost all forms of sarcoidosis, no pharmacologic treatments for sarcoidosis have been approved by the US Food and Drug Administration. Corticosteroids act mainly by repression of inflammatory genes including interferon-gamma (IFN- $\gamma$ ) and tumor necrosis factor (TNF)-alpha that are important cytokines in the development of the sarcoid granuloma. ${ }^{11,12} \mathrm{~A}$ number of additional inflammatory cytokines that are involved in granuloma formation and maintenance are responsive to the anti-inflammatory properties of corticosteroids. ${ }^{12}$

There is no prospective data to guide the dose, duration, or tapering of corticosteroids in sarcoidosis. Guiding principles are offered in the official sarcoidosis consensus statement of the American Thoracic Society (ATS)/European Respiratory Society (ERS)/World Association of Sarcoidosis and Other Granulomatous Diseases (WASOG). ${ }^{1}$

\section{Pulmonary sarcoidosis}

A Delphi study of sarcoidosis experts reached a consensus that corticosteroids are the drug of choice for pulmonary sarcoidosis. ${ }^{13}$ The ATS/ERS/WASOG consensus recommends a daily prednisone equivalent of $20-40 \mathrm{mg}$ for the initial treatment of pulmonary sarcoidosis. This dose should be continued for at least 1-3 months and then tapered to a $5-10 \mathrm{mg} /$ day maintenance dose for a total of 1 year of treatment before discontinuing. ${ }^{1}$ The rationale for a 1-year regimen is empiric and based on the unproven assumption 


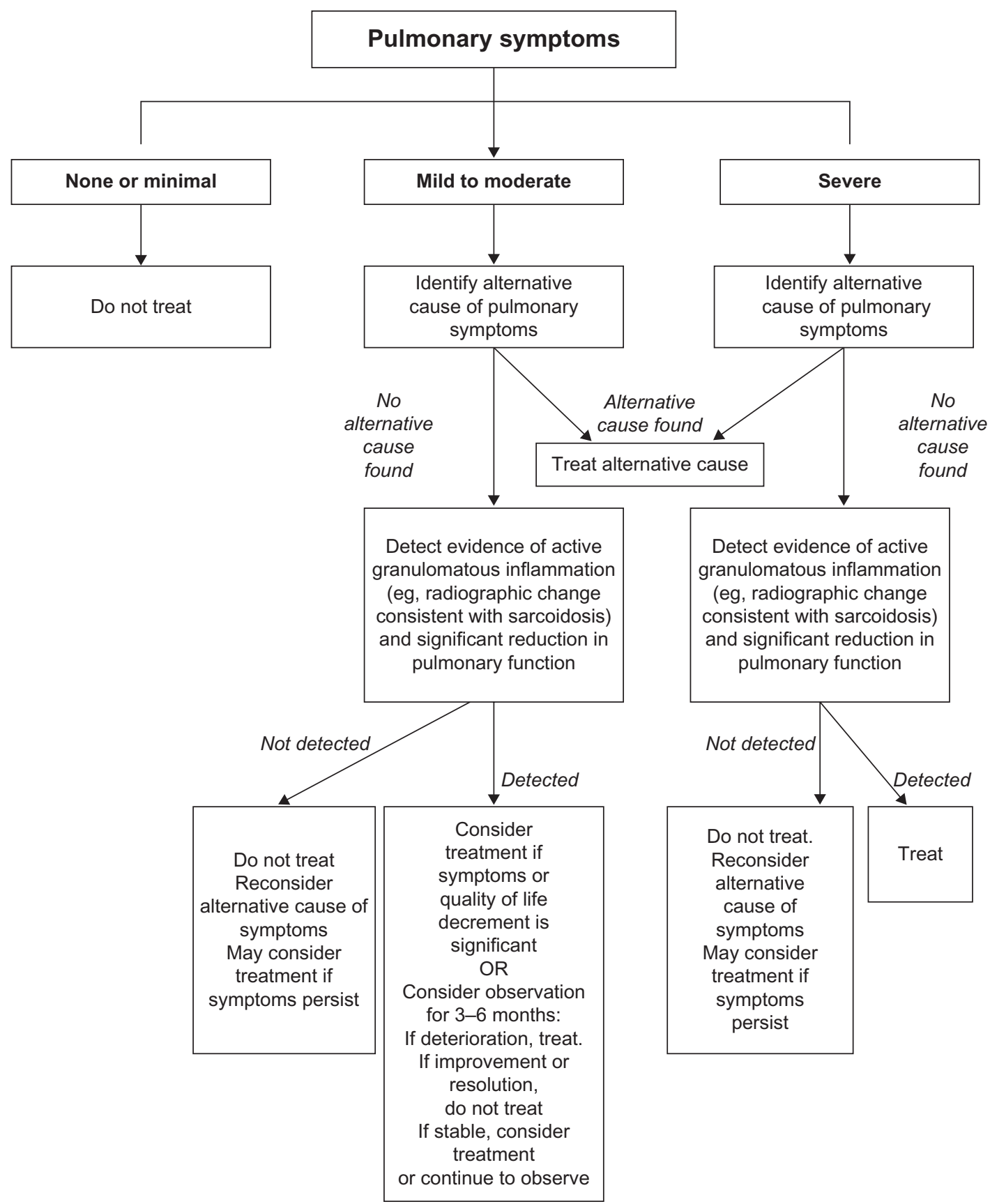

Figure 2 The general approach to the decision to treat pulmonary sarcoidosis.

Notes: (I) asymptomatic patients are not treated; (2) alternative causes for the pulmonary symptoms need to be excluded; (3) treatment is indicated for significant changes in significant symptoms as long as there is evidence of significant active pulmonary sarcoidosis and pulmonary dysfunction.

Adapted with permission from Judson MA. The treatment of pulmonary sarcoidosis. Respir Med. 20I2;106(I0):I35I-136I. ${ }^{3}$

that relapses are common with shorter-course regimens. This approach to treatment has been described as "the six phases of treatment for pulmonary sarcoidosis:" initial dosing, taper to maintenance, maintenance dosing, taper off, observation, treatment of relapse (Figure 3 ). ${ }^{2}$ The suggested corticosteroid doses and dosing intervals are described in the text of Figure 3. Several variations of treatment have been suggested such as: total duration of therapy for 6 months, maintenance phase where alternate day therapy is used to decrease side effects, and a lower initial dose and shorter initial phase. ${ }^{3}$ In general, in contrast to other organs involved with sarcoidosis (vide infra), pulmonary sarcoidosis is usually very sensitive to corticosteroid therapy.

Although treatment of pulmonary sarcoidosis with inhaled corticosteroids (ICS) has been studied, these data are inconclusive. ICS have been advocated for sarcoidosis 


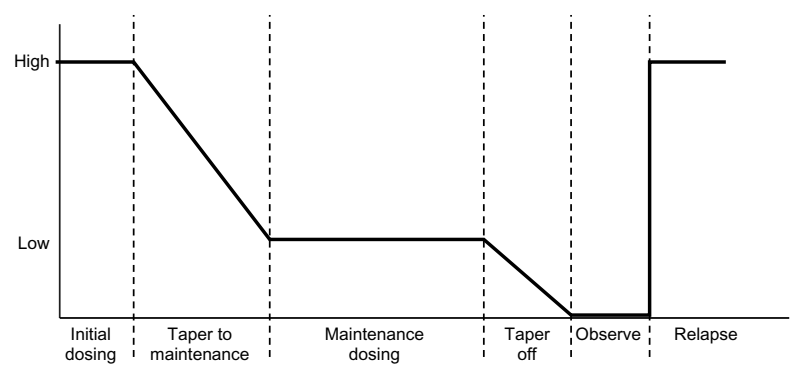

Figure 3 Corticosteroid (six-phase) treatment for pulmonary sarcoidosis. Notes: Initial dosing: $20-40 \mathrm{mg} /$ day of prednisone equivalent for 2-6 weeks; taper to maintenance: over I-6 months; maintenance dosing: 0.05-0.1 mg/day of prednisone equivalent until 3-9 months after initiation of therapy; taper off corticosteroid therapy: over I-3 months; monitor for relapse; treatment of relapse: same as initial corticosteroid dosing but additional corticosteroid sparing agents should be strongly considered.

Reproduced with permission from Judson MA. An approach to the treatment of pulmonary sarcoidosis with corticosteroids: the six phases of treatment. Chest. 1999; I 15(4): I 158-1 165.2

associated cough, although definite improvement of this symptom has not been demonstrated. ${ }^{14}$ In a randomized, double-blind, placebo-controlled study of 189 patients with recent-onset pulmonary sarcoidosis, subjects received either 3 months of systemic corticosteroids $(20 \mathrm{mg}$ /day of prednisolone tapering to $10 \mathrm{mg} /$ day) followed by 15 months of high-dose inhaled budesonide ( $800 \mu \mathrm{g}$ twice daily), or matching oral and inhaled placebos. After 5 years, statistically more patients in the placebo group had evidence of chest radiographic changes and more frequently required oral corticosteroids. ${ }^{15}$ Although this study was well designed, these results are discordant with several studies suggesting that corticosteroid treatment of sarcoidosis is associated with a greater risk of relapse. ${ }^{16-19}$ In addition, this was not a "pure ICS" study in that the treatment group also initially received 3 months of oral corticosteroids. Finally, the dose of ICS used in this trial was budesonide $800 \mu \mathrm{g}$ twice daily, which is costly within the US. A meta-analysis concerning ICS treatment of pulmonary sarcoidosis did not clearly demonstrate a benefit. ${ }^{20}$ The aforementioned Delphi study of sarcoidosis experts reached a consensus that ICS should not be used routinely to treat pulmonary sarcoidosis. ${ }^{13}$ ICS could be considered on an individual basis for pulmonary sarcoidosis patients with significant cough, or possibly, as an oral corticosteroid sparing agent.

\section{Extrapulmonary sarcoidosis}

Corticosteroids are also the initial drug of choice to treat most forms of extrapulmonary sarcoidosis. As a general rule, $20-40 \mathrm{mg}$ of daily prednisone equivalent is an adequate initial dose for most forms of extrapulmonary sarcoidosis. The corticosteroid dose should then be tapered to the lowest effective dose, with a specific clinically relevant endpoint in mind (Figure 1). Some nuances in the exact dosing schedules and type of corticosteroid, depending on the specific organ that is treated, will be discussed in the next section.

\section{Eye}

Sarcoidosis may cause an isolated anterior uveitis confined to the anterior chamber. Because topical corticosteroids (corticosteroid eyedrops) can penetrate into the anterior chamber, they can be used without oral corticosteroids in this instance. ${ }^{21}$ If there is an associated intermediate and/or posterior uveitis, topical corticosteroids will be inadequate and oral corticosteroids will be required. Intraocular corticosteroid injections may be given when eye sarcoidosis extends deeper than the anterior chamber. ${ }^{4}$ There is minimal evidence to support a specific approach, but most recommend a shorter course (eg, 3-6 months) of monotherapy with corticosteroids for sarcoid uveitis because both the disease itself and corticosteroid therapy can lead to cataracts and glaucoma. Therefore, corticosteroid-sparing agents are considered earlier than with other forms of sarcoidosis. Sarcoidosis may cause an acute optic neuritis which is visionthreatening. A sarcoidosis patient who develops sudden loss of vision or color vision should have this diagnosis immediately confirmed via a fundoscopic examination. If an acute sarcoid optic neuritis is confirmed, high dose intravenous corticosteroids (eg, $1 \mathrm{~g}$ daily of methylprednisolone sodium succinate for 3-5 days) should be strongly considered.

\section{Cardiac}

Although some have recommended high initial corticosteroid doses for cardiac sarcoidosis, ${ }^{22}$ many recommend $30 \mathrm{mg}$ of daily prednisone equivalent based on a Japanese series that found no difference in long-term survival between those who received at least $40 \mathrm{mg}$ of prednisone daily compared with those receiving $30 \mathrm{mg} /$ day or less. ${ }^{23} \mathrm{~A}$ Delphi study of cardiac sarcoidosis experts reached consensus that $30-40 \mathrm{mg}$ of daily prednisone equivalent be the initial treatment dose cardiac sarcoidosis. ${ }^{24}$

\section{Neurosarcoidosis}

Neurosarcoidosis is relatively refractory to corticosteroids. There are case series demonstrating up to 71 percent of patients being refractory to corticosteroids ${ }^{25}$ and relapses being common at $20-25 \mathrm{mg}$ of daily prednisone equivalent. ${ }^{26}$ For these reasons, some have recommended that the initial corticosteroid dose for neurosarcoidosis should be $40-80 \mathrm{mg}$ of daily prednisone equivalent. ${ }^{27}$ 


\section{Skin}

Cutaneous sarcoidosis almost never causes significant medical problems, and is, therefore, treated only if it is of cosmetic importance to the patient. The initial corticosteroid dose is $20-40 \mathrm{mg}$ of daily prednisone equivalent. For one or a few small lesions, intralesional injections of triamcinolone acetonide are often effective. ${ }^{28,29}$ Topical corticosteroid creams may be used in this case, although they are probably not as effective as intralesional injections..$^{29}$ Lupus pernio is a disfiguring facial form of cutaneous sarcoidosis. Although lupus pernio lesions usually improve on corticosteroid therapy, these lesions usually require infliximab therapy (vide infra) for significant resolution.

Joint

Nonsteroidal anti-inflammatory agents should be used prior to consideration of corticosteroid or other immunosuppressive therapy.

\section{Monitoring}

Patients receiving chronic corticosteroids need to be monitored for potential side effects. This includes monitoring weight and nutrition, blood pressure, cortical bone density, eye examinations (for the development of cataracts and/or glaucoma), diabetes mellitus/hyperglycemia, and mood changes. Prophylaxis against infection with Pneumocystis jirovecii is somewhat controversial as some experts have recommended therapy but this seems to be a rare event. ${ }^{30}$

\section{Additional anti-sarcoidosis agents When to consider additional agents}

Although corticosteroids are the initial drug of choice for almost all forms of sarcoidosis, additional agents are very commonly required. It is unusual for sarcoidosis to be unresponsive to corticosteroids. This may occasionally occur in cases of neurosarcoidosis, ${ }^{25}$ but almost never with pulmonary sarcoidosis or other forms of sarcoidosis. It is much more common for additional medications to be required because of the development of significant corticosteroid side effects. These corticosteroid side effects may present acutely with initial high dose corticosteroid treatment, such as mood and behavioral changes. Most commonly, these corticosteroid side effects develop slowly, as most of these side effects are the result of cumulative toxicity (eg, osteoporosis, weight gain). Therefore, patients with chronic sarcoidosis who need anti-sarcoidosis medication for long periods are at particular risk for corticosteroid toxicity, even if their sarcoidosis is being controlled on a relatively low dose of corticosteroids.
A Delphi study of sarcoidosis experts reached a consensus that a maintenance dose of greater than $10 \mathrm{mg}$ of daily prednisone equivalent was unacceptable, implying that corticosteroid sparing agents should be considered in such situations. ${ }^{13}$

In most situations, additional agents are added to corticosteroid therapy as corticosteroid sparing agents with the goal of reducing the chronic corticosteroid dose. Additional agents are infrequently sufficient to control sarcoidosis without the addition of at least small doses of corticosteroids. Corticosteroids are usually tapered to the lowest effective dose once these agents have been added. With the possible exception of infliximab, ${ }^{31}$ most of these additional agents take several months to be maximally effective. Therefore, too rapid a corticosteroid taper after additional agents have been added may falsely label these drugs as ineffective as corticosteroid sparing medications. Unless the corticosteroid side effects are major, it is recommended that corticosteroids not be tapered for at least 1 month after the addition of a second agent. As the above implies, complete discontinuation of corticosteroids is much less likely to be successful than tapering corticosteroids to a lower maintenance dose.

The rationale for selecting a specific additional drug for the treatment of sarcoidosis is problematic, as these data are limited, usually consist of uncontrolled case reports or case series, and have almost never involved head to head comparisons or randomized controlled trials. This decision is often based on the following factors: (1) the organ that is being treated, as some case reports and case series have involved specific sarcoidosis organ involvement; (2) the risk of drug toxicity in the individual patient; (3) ease of use; (4) cost. Although not evidence-based, two Delphi studies of sarcoidosis experts suggested favored drug choices for the treatment of pulmonary ${ }^{13}$ and cardiac ${ }^{24}$ sarcoidosis.

\section{Methotrexate}

Methotrexate is the most studied alternative medication to corticosteroids for the treatment of sarcoidosis. In a recent Delphi study of sarcoidosis experts, a consensus was reached that methotrexate was the preferred corticosteroid sparing agent for pulmonary sarcoidosis. ${ }^{13}$ Methotrexate acts by inhibiting the metabolism of folic acid.

Methotrexate has been found to have efficacy for most forms of sarcoidosis including lung, eye, skin, and neurologic involvement. ${ }^{32}$ Approximately two-thirds of sarcoidosis patients will respond to treatment. ${ }^{33}$ We believe that methotrexate is most useful in sarcoidosis as a corticosteroid sparing agent when corticosteroids have either been inadequate to 
completely control the disease and/or caused significant side effects. In approximately one-quarter of cases, sarcoidosis patients receiving methotrexate and corticosteroids can be weaned off the latter drug. ${ }^{32}$

The standard dose of methotrexate is from 10-25 mg weekly, although most clinicians use the lower end of that range (10-15 mg/week). ${ }^{34}$ Folic acid is often administered concomitantly. ${ }^{35}$

Nausea, malaise, and leucopenia are the most common adverse effects of methotrexate. Hepatotoxicity causing hepatic fibrosis, pulmonary toxicity, and opportunistic infections may also occur with this drug. The pregnancy risk of methotrexate is category $\mathrm{X}$ : it should not be used during pregnancy.

\section{Antimalarials}

Antimalarial agents such as chloroquine and hydroxychloroquine have immunomodulating properties, and they have been found to be effective in the treatment of sarcoidosis. The proposed mechanism of action includes the impairment of release of several cytokines and impaired antigen presentation by monocytes, macrophages, and dendritic cells to CD4-positive helper T-cells. ${ }^{36}$ Chloroquine has shown benefit in the treatment of pulmonary sarcoidosis but the data are quite limited. ${ }^{37}$ Chloroquine and hydroxychloroquine appear particularly effective for cutaneous sarcoidosis where they have been used as monotherapy or in combination with corticosteroids. ${ }^{38}$ Since the antimalarials may take several months to be maximally effective, we recommend using them for cutaneous sarcoidosis along with corticosteroids as the latter drug usually works much more rapidly. Attempts can be made to taper, if not discontinue corticosteroids over several months. Sarcoidosis-induced hypercalcemia and hypercalciuria have also been reported to respond to antimalarials, ${ }^{39-41}$ although in our experience, corticosteroids work more reliably for this problem. Antimalarials are also useful for the treatment of sarcoidosis-related arthritis. ${ }^{42}$

The major side effect of the antimalarials, especially chloroquine, is retinopathy. Therefore, a baseline eye exam and follow-up exam every 6-12 months is requisite. Additional side effects include nausea, agranulocytosis, and hemolysis in patients with glucose-6-phosphate deficiency. Hydroxychloroquine has a much smaller risk of retinal toxicity compared with chloroquine, but the latter drug appears more effective.

\section{Azathioprine}

Azathioprine is an anti-metabolite drug, which has been reported to be useful in the treatment of sarcoidosis.
Azathioprine is a prodrug that is converted in vivo to the active metabolite, 6-mercaptopurine by the enzyme, thiopurine-S-methyltransferase. As a purine analog, azathioprine acts to inhibit purine synthesis necessary for the proliferation of cells, especially $\mathrm{B}$ and $\mathrm{T}$ lymphocytes. Cellular immunity is suppressed to a greater degree than humoral immunity.

Azathioprine's strong suppressive effect on T-lymphocytes makes it an attractive treatment option for sarcoidosis, in which activated T-cells play a critical role. However, the usefulness of azathioprine for sarcoidosis has yet to be examined through a randomized controlled clinical trial. Most reports of azathioprine for the treatment of sarcoidosis have involved open label case series with a small number of patients. We believe that azathioprine is most likely to be useful in sarcoidosis as a corticosteroid sparing agent when corticosteroids have either been inadequate to completely control the disease and/or caused significant side-effects.

Azathioprine is usually initiated at a dose of $50 \mathrm{mg}$ per day. Increasing the dose by $25 \mathrm{mg}$ /day every 2-3 weeks reduces the likelihood of gastrointestinal side effects. The typical maintenance dose is $2 \mathrm{mg} / \mathrm{kg}$ with a maximum of $200 \mathrm{mg} /$ day. Dosing adjustments are made for renal insufficiency and/or adverse effects such as leukopenia. An initial clinical response usually occurs within 2-4 months. ${ }^{43}$

The major adverse effects of azathioprine include hematologic, gastrointestinal, and hepatotoxicity, a hypersensitivity syndrome, and carcinogenic and teratogenic risks. Women of childbearing age must use a reliable method of contraception during azathioprine therapy. Gastrointestinal upset, rash, fever, and malaise are the most common symptoms reported by patients. Azathioprine-induced hepatotoxicity is generally reversible following discontinuance of the drug. Complete blood counts and serum liver tests should be regularly monitored for drug toxicity.

\section{Leflunomide}

Leflunomide was originally developed as an analogue to methotrexate with less toxicity. It has been suggested to be useful for sarcoidosis in several case series. The active metabolite of leflunomide (A77 1726) exhibits anti-inflammatory activity by inhibiting cyclooxygenase- 2 (COX-2) and causes immunomodulation via its inhibition of dihydroorotate dehydrogenase, an enzyme responsible for de novo synthesis of pyrimidines. ${ }^{44}$ Ultimately, the drug prevents the expansion of activated lymphocytes via interference with cell cycle progression. Leflunomide also suppresses TNF- $\alpha$ signaling. 
Limited clinical data suggest that leflunomide may be as effective as methotrexate in patients with chronic sarcoidosis, but with less toxicity. ${ }^{45}$ The drug could be considered in sarcoidosis as a corticosteroid sparing agent when corticosteroids have either been inadequate to completely control the disease and/or caused significant side-effects. We suspect that it would be particularly useful in a sarcoidosis patient who received a beneficial response from methotrexate but developed a side effect from this drug.

The initial dose of leflunomide is typically $20 \mathrm{mg}$ per day. The dosage may be decreased to $10 \mathrm{mg}$ /day in patients who develop toxicity. Some have recommended administering a loading dose of $100 \mathrm{mg}$ daily for 3 days as the drug has a long half-life (typically 14-15 days) and takes a long time to achieve steady state levels. ${ }^{46}$ However, a loading dose is often omitted due to a greater incidence of side effects, especially in patients who are receiving the drug because of previous hepatic or hematologic toxicity from methotrexate use. ${ }^{47}$

As mentioned, previous trials (in rheumatoid arthritis) demonstrated that leflunomide had a superior side effect profile compared to methotrexate. ${ }^{48}$ Significant hepatic toxicity requiring drug withdrawal occurred at half the rate in the leflunomide group compared to those receiving methotrexate. Interstitial pneumonitis did not occur with leflunomide whereas it was seen in 5/320 (1.6\%) patients who received methotrexate that resulted in one death..$^{48}$ The most common side effects of leflunomide are nausea, diarrhea, abdominal pain, rash, alopecia, and peripheral neuropathy. Anemia occurs in $1 \%-10 \%$. Leflunomide is contraindicated in pregnancy (category X). Pregnancy must be excluded prior to initiating treatment. Contraception is required in both males and females of childbearing potential. Because the drug has a typical half-life of 14-15 days, if significant leflunomide toxicity develops, elimination may need to be enhanced by the administration of cholesytramine. ${ }^{49}$

\section{Mycophenolate}

Mycophenolate mofetil is a reversible inhibitor of inosine monophosphate dehydrogenase in purine biosynthesis that is necessary for the growth of T cells and B cells. It is a prodrug of mycophenolic acid.

Mycophenolate has not been used extensively for the treatment of sarcoidosis. It may be most useful for the treatment of neurosarcoidosis ${ }^{50}$ and cutaneous sarcoidosis. ${ }^{51}$ It may also be useful for other forms of sarcoidosis, although the data are quite limited..$^{51,52}$ We believe that the data concerning this drug are so minimal for the treatment of sarcoidosis that it should be considered as a third-line drug in sarcoidosis as a corticosteroid sparing agent when (a) corticosteroids have either been inadequate to completely control the disease and/or caused significant side-effects, and (b) other standard corticosteroid sparing agents have failed or have caused significant side effects. Mycophenolate might be more highly considered for cases of neurosarcoidosis.

The maintenance mycophenolate dose in sarcoidosis is usually $1000-1500 \mathrm{mg}$ given twice daily (2-3 g total daily dose). ${ }^{50,51}$ The dose is often escalated toward this maintenance dose while monitoring for toxicity such as cytopenias of serum liver enzyme elevations. ${ }^{50}$

The most common side effects of this drug are hyperglycemia, hypercholesterolemia and GI side-effects such as diarrhea and vomiting. Bone marrow suppression and hepatic dysfunction may occur. Mycophenolate is contraindicated in pregnancy as it is associated with fetal loss and congenital birth defects.

\section{Cyclophosphamide}

Cyclophosphamide is an alkylating agent that prevents cell division by cross-linking DNA strands and decreasing DNA synthesis. Its immunosuppressive and anti-inflammatory effects arise from a decrease in lymphocyte number and function.

Because of the risk of severe toxicity (vide infra) cyclophosphamide is used to treat sarcoidosis only in severe cases that have been refractory to corticosteroids and, usually, additional agents. In particular, cyclophosphamide has been used to treat neurosarcoidosis ${ }^{25,53}$ and cardiac sarcoidosis $\mathrm{s}^{54,55}$ because these forms of sarcoidosis may be life threatening. Even in some of these cases, infliximab is preferred and probably superior to cyclophosphamide. ${ }^{56}$

Cyclophosphamide is usually given intravenously rather than orally as the side effect profile is better with the former route of administration. Intravenous regimens are associated with approximately 50\% less cumulative cyclophosphamide than oral daily dosing and therefore less toxicity. ${ }^{57}$ The usual intravenous dose is $500-1000 \mathrm{mg}$ administered over 30-60 minutes once every $2-4$ weeks. ${ }^{25,53}$ Alternatively, a body surface area approach may be used with $0.5 \mathrm{gm} / \mathrm{m}^{2}$ of body surface area administered intravenously every 4 weeks. ${ }^{57}$

Cyclophosphamide may cause toxicity of the hematologic, dermatologic, metabolic, gastrointestinal, and genitourinary systems. Cyclophosphamide therapy, especially when oral and long-term, is associated with hemorrhagic cystitis as well as the development of transitional-cell carcinoma bladder. Cyclophosphamide interferes with oogenesis and 
spermatogenesis and may cause sterility in both men and women. Cyclophosphamide may also be teratogenic. Women of childbearing age must use a reliable method of contraception while receiving cyclophosphamide. ${ }^{58}$

\section{Tumor necrosis alpha antagonists}

Over the past several years, various series and clinical trials have reported efficacy of TNF- $\alpha$ antagonists for the treatment of sarcoidosis..$^{31,59-62}$ There is a sound rationale for this therapy because TNF- $\alpha$ is secreted by macrophages in patients with active sarcoidosis, ${ }^{63}$ and TNF- $\alpha$ is thought to be integrally involved in the development of the sarcoid granuloma. ${ }^{64}$

In a randomized, double-blinded clinical trial, infliximab was shown to be effective for pulmonary ${ }^{31}$ and extrapulmonary sarcoidosis. ${ }^{65}$ It may be particularly effective for lupus pernio ${ }^{66}$ (disfiguring facial sarcoidosis) and for neurosarcoidosis. ${ }^{56}$ Unlike almost all other second-line agents for sarcoidosis which typical require several months to reach maximum efficacy, infliximab often shows a therapeutic response within a few weeks. ${ }^{31}$

Despite the promising results of infliximab for the treatment of sarcoidosis, its expense and the fact that it requires regular intravenous infusions prevent the drug from being the drug of choice for most forms of sarcoidosis. We would position infliximab as a third-line agent after corticosteroids plus a corticosteroid sparing agent have failed to provide an adequate treatment response. As the limited data suggest, the drug is very effective for sarcoidosis, it could be considered in cases of severe sarcoidosis as a second line agent or given initially with corticosteroids in that situation. As mentioned, infliximab could be considered as a second line for the treatment of lupus pernio or neurosarcoidosis as the limited data suggest that it may be particularly effective for those forms of sarcoidosis.

The typical dosing of infliximab for sarcoidosis is $3-5 \mathrm{mg} / \mathrm{kg}$ with loading doses at weeks $0,2,6$, and then every 6 weeks thereafter. ${ }^{31}$ The maintenance dosing interval may then be adjusted according to the patient's response. As most of the patients who receive infliximab have a history of chronic, recalcitrant severe disease, most patients will relapse if the drug is discontinued. ${ }^{67}$ Therefore, infliximab therapy usually needs to be continued unless the patient is converted to another anti-sarcoidosis agent.

The side effects of infliximab include allergic reactions. Infliximab is a chimeric antibody with a murine-derived portion that is often the source of these allergic reactions. Although these reactions are rarely life threatening, the drug must be permanently discontinued if such reactions occur. These allergic reactions are often related to antibody formation against the murine portion of infliximab. Such antibody formation may also diminish the drug's efficacy. To prevent such antibody formation, some have advocated routinely using concomitant immunosuppressive medications (eg, low-dose methotrexate) whenever infliximab is used. Additional infliximab side effects include leukopenia and immunosuppression. In particular, latent tuberculosis infection can be reactivated by use of infliximab that may be life threatening. ${ }^{68}$ Therefore, all patients receiving the drug must be screened for tuberculosis with a tuberculin skin test or blood interferon release assay. Evidence of infliximab worsening congestive heart failure has prohibited the use of the drug with New York Heart Association Class 3 and 4 heart failure. Although controversial, ${ }^{69}$ the drug appears to be associated with an increased risk of malignancy, especially lymphoma. ${ }^{70}$ Neurologic complications including demyelination syndromes may rarely occur with infliximab. ${ }^{71}$

Other TNF- $\alpha$ antagonist biologicals have been used to treat sarcoidosis, with mixed results. Adalimumab appears to be useful for the treatment of sarcoidosis. It has advantages over infliximab is that it is a fully humanized antibody so that allergic reactions may be less frequent. Also, because adalimumab in given subcutaneously instead of intravenously, it is less cumbersome to use. Although medical evidence is limited, adalimumab often requires a relatively high dose (eg, $40 \mathrm{mg}$ subcutaneously every week) ${ }^{72}$ and a relatively long time period compared to infliximab to reach maximum efficacy. Etanercept appears not to be particularly useful for the treatment of sarcoidosis. ${ }^{73,74}$ Although all TNF- $\alpha$ antagonists may rarely induce exacerbations of sarcoidosis, this most commonly occurs with etanercept. ${ }^{75-78}$ It has been postulated that TNF- $\alpha$ antagonist-induced sarcoidosis may occur via stimulation of IFN- $\gamma$ production leading to the development of granulomatous inflammation. ${ }^{75}$ Oral TNF- $\alpha$ antagonist drugs such as thalidomide and apremilast may have some activity in sarcoidosis, although they do not appear to be very potent for this condition. ${ }^{59,79,80}$

\section{Other drugs}

Numerous other drugs have been reported to be effective for sarcoidosis in case reports and small case series. These include rituximab, ${ }^{81,82}$ tetracyclines (especially for skin sarcoidosis), ${ }^{83}$ and cyclosporine (although the drug was found not to be effective in a randomized trial for pulmonary sarcoidosis, ${ }^{84}$ it may be beneficial for neurosarcoidosis ${ }^{85}$ ).

Table 1, adapted from a previously published paper, ${ }^{86}$ lists the drug recommendations for various forms of sarcoidosis. Table 2 shows general drug dosing recommendations for sarcoidosis. 
Table I Drugs for the treatment of sarcoidosis

\begin{tabular}{|c|c|c|c|}
\hline \multirow[t]{2}{*}{ Organ } & \multirow[t]{2}{*}{ Manifestations } & \multicolumn{2}{|l|}{ Treatment } \\
\hline & & Drug of choice & Alternatives ${ }^{\pi T}$ \\
\hline Lung & & C & $M, A Z, L, C Q, I, A D$ \\
\hline \multirow[t]{3}{*}{ Eye } & Anterior uveitis: red eye, painful eye, photophobia & CED, CP & $C, M, A Z, L, I A D$ \\
\hline & Posterior uveitis: floaters, $\downarrow$ vision & C & $M, A Z, L, I, A D$ \\
\hline & Optic neuritis: sudden loss of vision or color vision & $C^{*}$ & $M, A Z, L, I, A D$ \\
\hline \multirow[t]{8}{*}{ Skin } & Erythema nodosum: pain erythematous/violaceous & NSAID ${ }^{\dagger}$ & C \\
\hline & lesions on extensor surface & & \\
\hline & Localized lesion(s) & $\mathrm{Cl}, \mathrm{CC}$ & C, M, AZ, L, H, CQ, \\
\hline & & & MY, I, AD, TET \\
\hline & Diffuse lesions & C & $\mathrm{M}, \mathrm{AZ}, \mathrm{L}, \mathrm{H}, \mathrm{CQ}$ \\
\hline & & & MY, I, AD, TET \\
\hline & Lupus pernio: disfiguring facial sarcoidosis & C & $I^{\ddagger}, \mathrm{M}, \mathrm{AZ}, \mathrm{L}, \mathrm{H}, \mathrm{CQ}$, \\
\hline & & & MY, AD \\
\hline \multirow[t]{5}{*}{ Liver } & Asymptomatic LFT $\uparrow$ & & Do not treat \\
\hline & Fever, nausea, vomiting & C & $M, A Z, L, H, C Q$, \\
\hline & & & $\mathrm{I}, \mathrm{AD}$ \\
\hline & Pruritus, cholestasis & $\mathrm{C}^{\S}$ & $\mathrm{M}, \mathrm{AZ}, \mathrm{L}, \mathrm{H}, \mathrm{CQ}$ \\
\hline & & & $\mathrm{I}, \mathrm{AD}$ \\
\hline \multirow[t]{4}{*}{ Joints } & Arthritis & NSAID & $\mathrm{C}, \mathrm{H}, \mathrm{CQ}, \mathrm{M}, \mathrm{AZ}$, \\
\hline & & & L, I, AD \\
\hline & Joint destruction & C & $\mathrm{H}, \mathrm{CQ}, \mathrm{M}, \mathrm{AZ}, \mathrm{L}$, \\
\hline & & & $\mathrm{I}, \mathrm{AD}$ \\
\hline \multirow[t]{6}{*}{ Heart } & Symptomatic heart block & $C \|, \pi$ & M, L, CYC, I**, \\
\hline & & & $A D^{* *}$ \\
\hline & Symptomatic arrhythmia & Cll, tr, , +f & M, L, CYC, I**, \\
\hline & & & $A D * *$ \\
\hline & Left ventricular dysfunction & 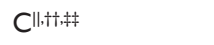 & M, L, CYC, I**, \\
\hline & & & $A D * *$ \\
\hline \multirow[t]{4}{*}{ Neurologic } & Mild to moderate & $\mathrm{C}^{\| \prime}$ & $\mathrm{M}, \mathrm{H}, \mathrm{CQ}, \mathrm{MY}$ \\
\hline & & & CYC, AD, $I^{\ddagger}$ \\
\hline & Severe (eg, seizures, coma) & $C^{*}$ & $\mathrm{M}, \mathrm{H}, \mathrm{CQ}, \mathrm{MY}$ \\
\hline & & & CYC, AD, $1^{\ddagger}$ \\
\hline \multirow[t]{3}{*}{ Hypercalcemia } & Asymptomatic, serum calcium $<1 \mathrm{I} \mathrm{mg} / \mathrm{dL}$ & High fluid intake & $\mathrm{C}, \mathrm{H}, \mathrm{CQ}, \mathrm{I}, \mathrm{AD}$ \\
\hline & Asymptomatic, serum calcium $\geq 1 \mathrm{I} \mathrm{mg} / \mathrm{dL}$ & C & $\mathrm{H}, \mathrm{CQ}, \mathrm{I}, \mathrm{AD}$ \\
\hline & Nephrolithiasis, serum creatinine $\uparrow$ & C & $\mathrm{H}, \mathrm{CQ}, \mathrm{I}, \mathrm{AD}$ \\
\hline \multirow[t]{2}{*}{ Sinus } & Nasal obstruction, epistaxis, crusting, hoarseness & $C \$ \$$ & $M, L, A Z, I, A D$ \\
\hline & Airway compromise & CIIII & $M, L, A Z, I, A D$ \\
\hline
\end{tabular}

Notes: $\uparrow$ increase; $\downarrow$ decrease; *consider $0.5-1$ g intravenous methylprednisolone for 3-5 days followed by $40-80$ mg/day prednisone equivalent; ${ }^{\dagger}$ for associated arthritis; ${ }^{\ddagger}$ may be the preferred drug after corticosteroids; §addition of ursodeoxycholate often beneficial; "consider high-dose corticosteroids: $40-80$ mg prednisone daily equivalent/day; "consider pacemaker or internal defibrillator placement; **contraindicated for New York Heart Association Class III and IV heart failure; ${ }^{\dagger \dagger}$ consider internal defibrillator placement; ${ }^{\ddagger}$ consider heart transplantation; ${ }^{85}$ corticosteroid injection if localized; IIII consider surgery; 17 usually corticosteroid sparing: require low-dose corticosteroids. Adapted with permission from Judson MA. The management of sarcoidosis by the primary care physician. Am J Med. 2007; $120(5): 403-407$. (C) 2007 Elsevier.

Abbreviations: AD, adalimumab; AZ, azathioprine; C, corticosteroids (usually 20-40 mg prednisone equivalent/day); CC, corticosteroid creams; CED, corticosteroid eye drops; Cl, corticosteroid injections; CP, cycloplegics; CQ, chloroquine; CYC, cyclophosphamide; H, hydroxychloroquine; I, infliximab; L, leflunomide; LFT, liver function tests; M, methotrexate; MY, mycophenolate; NSAID, nonsteroidal anti-inflammatory drugs; TET, tetracycline drugs.

\section{Potential therapies for sarcoidosis}

Ideally, pharmacotherapy for sarcoidosis should be based on a complete understanding of disease immunopathogenesis, with compounds developed that target specific portions of relevant inflammatory pathways. Unfortunately, the immunopathogenesis of sarcoidosis is not completely understood.

Figure 4 shows the proposed general schema leading to the development of the sarcoid granuloma. It is thought the process starts with the presentation of an antigen to an antigen-presenting cell (APC). The antigen is then processed by the APC and presented to a T-cell receptor by means of a human leukocyte antigen (HLA) molecule. The T-cells involved are usually of the $\mathrm{CD}+4$ class. Such binding involves the secretion of numerous cytokines from various cells as well as the formation of additional bridging molecules, only a handful of which are depicted in Figure 4. These cytokines and bridging molecules cause polarization of T-cells to a T-helper-1 (Th1) phenotype, T-cell prolif- 
Table 2 Drug dosing of treatment of sarcoidosis

\begin{tabular}{|c|c|c|}
\hline Drug & Dose & Comments \\
\hline Corticosteroids & $\begin{array}{l}20-40 \mathrm{mg} / \text { day of prednisone } \\
\text { equivalent }\end{array}$ & See Table I for special situations requiring a higher dose \\
\hline Methotrexate & $10-25 \mathrm{mg} /$ week & Monitor CBC, LFT \\
\hline Azathioprine & $50-200 \mathrm{mg} /$ day & Monitor CBC, LFT \\
\hline Leflunomide & $10-20 \mathrm{mg} / \mathrm{day}$ & $\begin{array}{l}\text { May give a loading dose of } 100 \mathrm{mg} / \text { day for } 3 \text { days } \\
\text { Monitor CBC, LFT }\end{array}$ \\
\hline Hydroxychloroquine & $200-400 \mathrm{mg} /$ day & Requires regular ophthalmology examination \\
\hline Chloroquine & $250-750 \mathrm{mg} /$ day & $\begin{array}{l}\text { Requires regular ophthalmology examination } \\
\text { Has higher rate of retinal toxicity than hydroxychloroquine }\end{array}$ \\
\hline Mycophenolate & $1000-1500 \mathrm{mg}$ twice daily & Monitor CBC, LFT \\
\hline Cyclosporine & $\begin{array}{l}500-1000 \mathrm{mg} \text { IV or } 500 \mathrm{mg} / \mathrm{m}^{2} \mathrm{IV} \\
\text { every } 3-4 \text { weeks }\end{array}$ & $\begin{array}{l}\text { Intravenous route preferred over oral because of less toxicity } \\
\text { Monitor } \mathrm{CBC} \text {, hematuria }\end{array}$ \\
\hline Infliximab & $\begin{array}{l}3-5 \mathrm{mg} / \mathrm{kg} \mathrm{IV} \text { at weeks } 0,2 \text {, and } 6 \text {, } \\
\text { then every } 6 \text { weeks }\end{array}$ & $\begin{array}{l}\text { Requires negative tuberculin skin test or interferon release } \\
\text { assay prior to use. Monitor } C B C \text {, exposure to } T B / \text { other } \\
\text { infectious pathogens }\end{array}$ \\
\hline Adalimumab & $\begin{array}{l}40 \mathrm{mg} \text { subcutaneous injection every } \\
\mathrm{I}-2 \text { weeks }\end{array}$ & $\begin{array}{l}\text { Usually } 40 \mathrm{mg} \text { subcutaneous injection every week is } \\
\text { required or higher dose }\end{array}$ \\
\hline
\end{tabular}

Abbreviations: CBC, complete blood count; IV, intravenously; LFT, liver function tests; TB, tuberculosis.

eration, recruitment of monocytes that are differentiated into macrophages leading to the formation of the sarcoid granuloma. ${ }^{34}$

Most pharmacotherapy for pulmonary sarcoidosis has not targeted specific portions of this inflammatory process. Corticosteroids inhibit the expression of many inflammatory cytokines including interleukin (IL)-1, IL-2, IL-4,
IL-5, IL-6, IL-8, IL-11, IL-12, IL-19, IFN- $\gamma$, and TNF- $\alpha .^{87}$ Corticosteroids also inhibit aracidonic acid metabolism, downregulate T-cell immunity, diminish T-cell activation, and enhance apoptosis of activated T-cells..$^{87,88}$ The mechanisms relevant to suppression of the granulomtous inflammation in sarcoidosis may involve all of these effects. ${ }^{87}$ Many other anti-sarcoidosis therapies such as methotrexate, azathioprine,

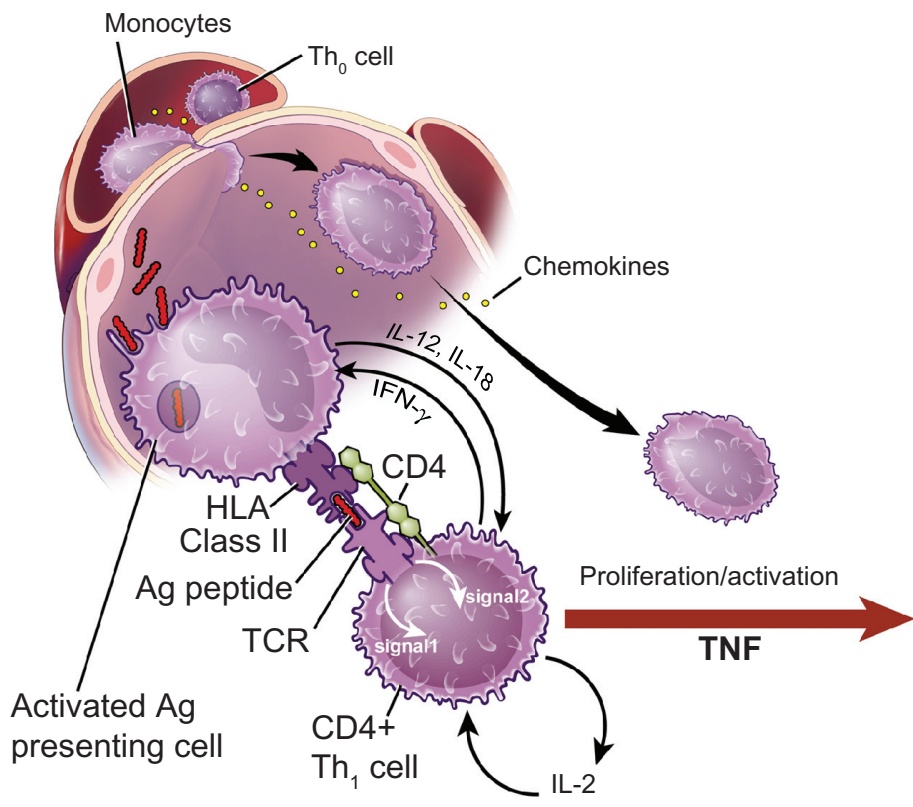

Figure 4 A proposed basic scenario for the immunopathogenesis of sarcoidosis.

Notes: APCs engulf and then process the unknown sarcoidosis antigen(s). The antigen is presented to a T-cell receptor on a T lymphocyte via HLA Class II molecules. This results in T-cell activation, T-cell proliferation, and monocyte recruitment and differentiation into macrophages. Various cytokines are depicted associated with these various processes, although numerous other inflammatory molecules and cell bridging molecules are involved.

Reprinted with permission from Baughman RP, Culver DA, Judson MA. A concise review of pulmonary sarcoidosis. Am J Respir Crit Care Med. 20I I; I83(5):573-58I. ${ }^{34}$ Reprinted with permission of the American Thoracic Society. Copyright (C) 2013 American Thoracic Society.

Abbreviations: CCF, Cleveland Clinic Foundation; HLA, human leukocyte antigen; IFN- $\gamma$, interferon-gamma; IL, interleukin; TCR, T cell receptor; TNF, tumor necrosis factor. 
and cyclophosphamide affect DNA and RNA production, and therefore, nonspecifically inhibit lymphocyte proliferation and function.

TNF- $\alpha$ antagonists represent a specific therapy targeted against an important building block of the sarcoid granuloma. Future therapies may target other specific inflammatory mediators involved in granuloma formation. Other potential therapies could be directed against the formation of the (APC)-(HLA molecule)-(processed antigen)-(T-cell receptor)-(T-cell) structure (Figure 4). This could be achieved by competitive inhibitors or by blocking molecules. This structure is thought to be required in order for T-cell activation, proliferation, and monocyte recruitment to occur, resulting in the sarcoid granuloma. Disruption of T-cell signaling may also disturb this model and would be a promising therapy for sarcoidosis. Finally, recent data suggest that sarcoidosis may be the result of continuous exposure of antigen to the immune system resulting in T-cell exhaustion. This may be precipitated by the presence of an amyloid substance that not only presents the sarcoid antigen but prevents it from being cleared via normal immune clearance mechanisms. ${ }^{89}$ Perhaps an "anti-amyloid therapy" would result in degradation of the sarcoid antigen such that granulomatous inflammation would cease. As Toll-like receptor 2 may be involved with this amyloid formation, ${ }^{89}$ drugs directed against this inflammatory molecule may be beneficial.

\section{Conclusion}

The treatment of sarcoidosis is not standardized. It is primarily driven by the effect of sarcoidosis upon the patient's symptoms and quality of life. In a large percentage of sarcoidosis patients, treatment is not indicated. Corticosteroids are the drug of choice for most forms of sarcoidosis. When corticosteroids are required chronically, corticosteroid sparing agents should be strongly considered.

\section{Disclosure}

Drs Beegle, Barba, and Gobunsuy have no conflicts of interest to disclose. Dr Judson is a consultant for Janssen and Celgene.

\section{References}

1. Hunninghake GW, Costabel U, Ando M, et al. ATS/ERS/WASOG statement on sarcoidosis. American Thoracic Society/European Respiratory Society/World Association of Sarcoidosis and other Granulomatous Disorders. Sarcoidosis Vasc Diffuse Lung Dis. 1999;16(2):149-173.

2. Judson MA. An approach to the treatment of pulmonary sarcoidosis with corticosteroids: the six phases of treatment. Chest. 1999;115(4): 1158-1165.

3. Judson MA. The treatment of pulmonary sarcoidosis. Respir Med. 2012;106(10):1351-1361.

4. Ohara K, Judson MA, Baughman RP. Clinical aspects of ocular sarcoidosis. Eur Respir Mon. 2005;10:188-209.
5. Rosen Y. Pathology of sarcoidosis. Semin Respir Crit Care Med. 2007;28(1):36-52.

6. Bell NH, Stern PH, Pantzer E, Sinha TK, DeLuca HF. Evidence that increased circulating 1 alpha, 25-dihydroxyvitamin $\mathrm{D}$ is the probable cause for abnormal calcium metabolism in sarcoidosis. $J$ Clin Invest. 1979;64(1):218-225.

7. Burke RR, Rybicki BA, Rao DS. Calcium and vitamin D in sarcoidosis: how to assess and manage. Semin Respir Crit Care Med. 2010;31(4): 474-484.

8. Sharma OP. Renal sarcoidosis and hypercalcemia. Eur Respir Mon. 2005;32:220-232.

9. Smedema JP, Snoep G, van Kroonenburgh MP, et al. Cardiac involvement in patients with pulmonary sarcoidosis assessed at two university medical centers in The Netherlands. Chest. 2005;128(1):30-35.

10. Judson MA, Gilbert GE, Rodgers JK, Greer CF, Schabel SI. The utility of the chest radiograph in diagnosing exacerbations of pulmonary sarcoidosis. Respirology. 2008;13(1):97-102.

11. Iannuzzi MC, Rybicki BA, Teirstein AS. Sarcoidosis. $N$ Engl J Med. 2007;357(21):2153-2165.

12. Grutters JC, van den Bosch JM. Corticosteroid treatment in sarcoidosis. Eur Respir J. 2006;28(3):627-636.

13. Schutt AC, Bullington WM, Judson MA. Pharmacotherapy for pulmonary sarcoidosis: a Delphi consensus study. Respir Med. 2010; 104(5):717-723.

14. Baughman RP, Iannuzzi MC, Lower EE, et al. Use of fluticasone in acute symptomatic pulmonary sarcoidosis. Sarcoidosis Vasc Diffuse Lung Dis. 2002;19(3):198-204.

15. Pietinalho A, Tukiainen P, Haahtela T, Persson T, Selroos O. Early treatment of stage II sarcoidosis improves 5-year pulmonary function. Chest. 2002;121(1):24-31.

16. Gottlieb JE, Israel HL, Steiner RM, Triolo J, Patrick H. Outcome in sarcoidosis. The relationship of relapse to corticosteroid therapy. Chest. 1997;111(3):623-631.

17. Eule H, Weinecke A, Roth I, Wuthe H. The possible influence of corticosteroid therapy on the natural course of pulmonary sarcoidosis. Late results of a continuing clinical study. Ann N Y Acad Sci. 1986; 465:695-701.

18. Izumi T. Sarcoidosis in Kyoto (1963-1986). Sarcoidosis. 1988;5(2): 142-146.

19. Rodrigues SC, Rocha NA, Lima MS, et al. Factor analysis of sarcoidosis phenotypes at two referral centers in Brazil. Sarcoidosis Vasc Diffuse Lung Dis. 2011;28(1):34-43.

20. Paramothayan NS, Lasserson TJ, Jones PW. Corticosteroids for pulmonary sarcoidosis. Cochrane Database Syst Rev. 2005;2:CD001114.

21. Baughman RP, Lower EE, Kaufman AH. Ocular sarcoidosis. Semin Respir Crit Care Med. 2010;31(4):452-462.

22. Nunes H, Freynet O, Naggara N, et al. Cardiac sarcoidosis. Semin Respir Crit Care Med. 2010;31(4):428-441.

23. Yazaki Y, Isobe M, Hiroe M, et al. Prognostic determinants of longterm survival in Japanese patients with cardiac sarcoidosis treated with prednisone. Am J Cardiol. 2001;88(9):1006-1010.

24. Hamzeh NY, Wamboldt FS, Weinberger HD. Management of cardiac sarcoidosis in the United States: a Delphi study. Chest. 2012; 141(1):154-162.

25. Lower EE, Broderick JP, Brott TG, Baughman RP. Diagnosis and management of neurological sarcoidosis. Arch Intern Med. 1997; 157(16):1864-1868.

26. Zajicek JP, Scolding NJ, Foster O, et al. Central nervous system sarcoidosis - diagnosis and management. QJM. 1999;92(2):103-117.

27. Sharma OP. Neurosarcoidosis: a personal perspective based on the study of 37 patients. Chest. 1997;112(1):220-228.

28. Marchell RM, Judson MA. Cutaneous sarcoidosis. Semin Respir Crit Care Med. 2010;31(4):442-451.

29. Haimovic A, Sanchez M, Judson MA, Prystowsky S. Sarcoidosis: a comprehensive review and update for the dermatologist: part I. Cutaneous disease. J Am Acad Dermatol. 2012;66(5):699. e691-e618; quiz 717-698. 
30. Lazar CA, Culver DA. Treatment of sarcoidosis. Semin Respir Crit Care Med. 2010;31(4):501-518.

31. Baughman RP, Drent M, Kavuru M, et al. Infliximab therapy in patients with chronic sarcoidosis and pulmonary involvement. Am J Respir Critl Care Med. 2006;174(7):795-802.

32. Lower EE, Baughman RP. Prolonged use of methotrexate for sarcoidosis. Arch Intern Med. 1995;155(8):846-851.

33. Baughman RP, Costabel U, du Bois RM. Treatment of sarcoidosis. Clin Chest Med. 2008;29(3):533-548, ix-X.

34. Baughman RP, Culver DA, Judson MA. A concise review of pulmonary sarcoidosis. Am J Respir Crit Care Med. 2011;183(5):573-581.

35. Morgan SL, Baggott JE, Vaughn WH, et al. Supplementation with folic acid during methotrexate therapy for rheumatoid arthritis. A double-blind, placebo-controlled trial. Ann Intern Med. 1994;121(11) 833-841.

36. Kalia S, Dutz JP. New concepts in antimalarial use and mode of action in dermatology. Dermatol Ther. 2007;20(4):160-174.

37. Baltzan M, Mehta S, Kirkham TH, Cosio MG. Randomized trial of prolonged chloroquine therapy in advanced pulmonary sarcoidosis. Am Journal Respir Crit Care Med. 1999;160(1):192-197.

38. Jones E, Callen JP. Hydroxychloroquine is effective therapy for control of cutaneous sarcoidal granulomas. J Am Acad Dermatol. 1990; 23(3 Pt 1):487-489.

39. Adams JS, Diz MM, Sharma OP. Effective reduction in the serum 1,25-dihydroxyvitamin D and calcium concentration in sarcoidosisassociated hypercalcemia with short-course chloroquine therapy. Ann Internal Med. 1989;111(5):437-438.

40. BarrePE, Gascon-Barre M, Meakins JL, Goltzman D. Hydroxychloroquine treatment of hypercalcemia in a patient with sarcoidosis undergoing hemodialysis. Am J Med. 1987;82(6):1259-1262.

41. O'Leary TJ, Jones G, Yip A, Lohnes D, Cohanim M, Yendt ER. The effects of chloroquine on serum 1,25-dihydroxyvitamin D and calcium metabolism in sarcoidosis. $N$ Engl J Med. 1986;315(12):727-730.

42. Sweiss NJ, Patterson K, Sawaqed R, et al. Rheumatologic manifestations of sarcoidosis. Semin Respir Crit Care Med. 2010;31(4):463-473.

43. Baughman RP, Lower EE. Steroid-sparing alternative treatments for sarcoidosis. Clin Chest Med. 1997;18(4):853-864.

44. Ruckemann K, Fairbanks LD, Carrey EA, et al. Leflunomide inhibits pyrimidine de novo synthesis in mitogen-stimulated T-lymphocytes from healthy humans. J Biol Chem. 1998;273(34):21682-21691.

45. Sahoo DH, Bandyopadhyay D, Xu M, et al. Effectiveness and safety of leflunomide for pulmonary and extrapulmonary sarcoidosis. Eur Respir J. 2011;38(5):1145-1150.

46. Baughman RP, Lower EE. Leflunomide for chronic sarcoidosis. Sarcoidosis Vasc Diffuse Lung Dis. 2004;21(1):43-48.

47. Smolen JS, Emery P, Kalden JR, et al. The efficacy of leflunomide monotherapy in rheumatoid arthritis: towards the goals of disease modifying antirheumatic drug therapy. J Rheumatol Suppl. 2004;71:13-20.

48. Emery P, Breedveld FC, Lemmel EM, et al. A comparison of the efficacy and safety of leflunomide and methotrexate for the treatment of rheumatoid arthritis. Rheumatology (Oxford). 2000;39(6):655-665.

49. van Riel PL, Smolen JS, Emery P, et al. Leflunomide: a manageable safety profile. J Rheumatol Suppl. 2004;71:21-24.

50. Androdias G, Maillet D, Marignier R, et al. Mycophenolate mofetil may be effective in CNS sarcoidosis but not in sarcoid myopathy. Neurology. 2011;76(13):1168-1172.

51. Kouba DJ, Mimouni D, Rencic A, Nousari HC. Mycophenolate mofetil may serve as a steroid-sparing agent for sarcoidosis. $\mathrm{Br} J$ Dermatol. 2003;148(1):147-148.

52. Bhat P, Cervantes-Castaneda RA, Doctor PP, Anzaar F, Foster CS. Mycophenolate mofetil therapy for sarcoidosis-associated uveitis. Ocul Immunol Inflamm. 2009;17(3):185-190.

53. Doty JD, Mazur JE, Judson MA. Treatment of corticosteroid-resistant neurosarcoidosis with a short-course cyclophosphamide regimen. Chest. 2003;124(5):2023-2026.

54. Chapelon-Abric C, de Zuttere D, Duhaut P, et al. Cardiac sarcoidosis: a retrospective study of 41 cases. Medicine. 2004;83(6):315-334.
55. Demeter SL. Myocardial sarcoidosis unresponsive to steroids. Treatment with cyclophosphamide. Chest. 1988;94(1):202-203.

56. Sodhi M, Pearson K, White ES, Culver DA. Infliximab therapy rescues cyclophosphamide failure in severe central nervous system sarcoidosis. Respir Med. 2009;103(2):268-273.

57. Haubitz M, Schellong S, Gobel U, et al. Intravenous pulse administration of cyclophosphamide versus daily oral treatment in patients with antineutrophil cytoplasmic antibody-associated vasculitis and renal involvement: a prospective, randomized study. Arthritis Rheum. 1998;41(10):1835-1844.

58. Somers EC, Marder W, Christman GM, Ognenovski V, McCune WJ. Use of a gonadotropin-releasing hormone analog for protection against premature ovarian failure during cyclophosphamide therapy in women with severe lupus. Arthritis Rheum. 2005;52(9):2761-2767.

59. Judson MA, Silvestri J, Hartung C, Byars T, Cox CE. The effect of thalidomide on corticosteroid-dependent pulmonary sarcoidosis. Sarcoidosis Vasc Diffuse Lung Dis. 2006;23(1):51-57.

60. Zabel P, Entzian P, Dalhoff K, Schlaak M. Pentoxifylline in treatment of sarcoidosis. Am J Respir Crit Care Med. 1997;155(5):1665-1669.

61. Doty JD, Mazur JE, Judson MA. Treatment of sarcoidosis with infliximab. Chest. 2005;127(3):1064-1071.

62. Baughman RP, Lower EE. Infliximab for refractory sarcoidosis. Sarcoidosis Vasc Diffuse Lung Dis. 2001;18(1):70-74.

63. Fehrenbach H, Zissel G, Goldmann T, et al. Alveolar macrophages are the main source for tumour necrosis factor-alpha in patients with sarcoidosis. Eur Respir J. 2003;21(3):421-428.

64. Zissel G, Muller-Quernheim J. Sarcoidosis: historical perspective and immunopathogenesis (Part I). Respir Med. 1998;92(2):126-139.

65. Judson MA, Baughman RP, Costabel U, et al. Efficacy of infliximab in extrapulmonary sarcoidosis: results from a randomised trial. Eur Respir J. 2008;31(6):1189-1196.

66. Stagaki E, Mountford WK, Lackland DT, Judson MA. The treatment of lupus pernio: results of 116 treatment courses in 54 patients. Chest. 2009;135(2):468-476

67. Panselinas E, Rodgers JK, Judson MA. Clinical outcomes in sarcoidosis after cessation of infliximab treatment. Respirology. 2009; 14(4):522-528.

68. Keane J, Gershon S, Wise RP, et al. Tuberculosis associated with infliximab, a tumor necrosis factor alpha-neutralizing agent. $N$ Engl J Med. 2001;345(15):1098-1104.

69. Lopez-Olivo MA, Tayar JH, Martinez-Lopez JA, et al. Risk of malignancies in patients with rheumatoid arthritis treated with biologic therapy: a meta-analysis. JAMA. 2012;308(9):898-908.

70. Cush JJ, Dao KH. Malignancy risks with biologic therapies. Rheum Dis Clin North Am. 2012;38(4):761-770.

71. Nozaki K, Silver RM, Stickler DE, et al. Neurological deficits during treatment with tumor necrosis factor-alpha antagonists. Am J Med Sci. 2011;342(5):352-355.

72. Erckens RJ, Mostard RL, Wijnen PA, Schouten JS, Drent M. Adalimumab successful in sarcoidosis patients with refractory chronic non-infectious uveitis. Graefes Arch Clin Exp Ophthalmol. 2012;250(5):713-720.

73. Baughman RP, Lower EE, Bradley DA, Raymond LA, Kaufman A. Etanercept for refractory ocular sarcoidosis: results of a double-blind randomized trial. Chest. 2005;128(2):1062-1047.

74. Utz JP, Limper AH, Kalra S, et al. Etanercept for the treatment of stage II and III progressive pulmonary sarcoidosis. Chest. 2003;124(1):177-185.

75. Louie GH, Chitkara P, Ward MM. Relapse of sarcoidosis upon treatment with etanercept. Ann Rheum Dis. 2008;67(6):896-898.

76. van der Stoep D, Braunstahl GJ, van Zeben J, Wouters J. Sarcoidosis during anti-tumor necrosis factor-alpha therapy: no relapse after rechallenge. J Rheumatol. 2009;36(12):2847-2848.

77. Verschueren K, Van Essche E, Verschueren P, Taelman V, Westhovens R. Development of sarcoidosis in etanercept-treated rheumatoid arthritis patients. Clin Rheumatol. 2007;26(11):1969-1971.

78. Burns AM, Green PJ, Pasternak S. Etanercept-induced cutaneous and pulmonary sarcoid-like granulomas resolving with adalimumab. JCutan Pathol. 2012;39(2):289-293. 
79. Baughman RP, Judson MA, Teirstein AS, Moller DR, Lower EE. Thalidomide for chronic sarcoidosis. Chest. 2002;122(1):227-232.

80. Baughman RP, Judson MA, Ingledue R, Craft NL, Lower EE. Efficacy and safety of apremilast in chronic cutaneous sarcoidosis. Arch Dermatol. 2012;148(2):262-264.

81. Lower EE, Baughman RP, Kaufman AH. Rituximab for refractory granulomatous eye disease. Clin Ophthalmol. 2012;6:1613-1618.

82. Bomprezzi R, Pati S, Chansakul C, Vollmer T. A case of neurosarcoidosis successfully treated with rituximab. Neurology. 2010;75(6):568-570.

83. Bachelez H, Senet P, Cadranel J, Kaoukhov A, Dubertret L. The use of tetracyclines for the treatment of sarcoidosis. Arch Dermatol. 2001; 137(1):69-73.

84. Wyser CP, van Schalkwyk EM, Alheit B, Bardin PG, Joubert JR. Treatment of progressive pulmonary sarcoidosis with cyclosporin A. A randomized controlled trial. Am J Respir Crit Care Med. 1997; 156(5):1371-1376.
85. Stern BJ, Schonfeld SA, Sewell C, Krumholz A, Scott P, Belendiuk G. The treatment of neurosarcoidosis with cyclosporine. Arch Neurol. 1992;49(10):1065-1072.

86. Judson MA. The management of sarcoidosis by the primary care physician. Am J Med. 2007;120(5):403-407.

87. Petrache I, Moller DR. Mechanism of therapy for sarcoidosis. In: Baughman RP, editor. Sarcoidosis. New York, NY: Taylor and Francis Group; 2006;210:671-687.

88. Khalil N, Whitman C, Zuo L, Danielpour D, Greenberg A. Regulation of alveolar macrophage transforming growth factor-beta secretion by corticosteroids in bleomycin-induced pulmonary inflammation in the rat. J Clinical Invest. 1993;92(4):1812-1818.

89. Chen ES, Song Z, Willett MH, et al. Serum amyloid A regulates granulomatous inflammation in sarcoidosis through Toll-like receptor-2. Am J Respir Crit Care Med. 2010;181(4):360-373.

\section{Publish your work in this journal}

Drug Design, Development and Therapy is an international, peerreviewed open-access journal that spans the spectrum of drug design and development through to clinical applications. Clinical outcomes, patient safety, and programs for the development and effective, safe, and sustained use of medicines are a feature of the journal, which has also been accepted for indexing on PubMed Central. The manuscript management system is completely online and includes a very quick and fair peer-review system, which is all easy to use. Visit http://www.dovepress.com/testimonials.php to read real quotes from published authors.

Submit your manuscript here: http://www.dovepress.com/drug-design-development-and-therapy-journal 